\title{
RESPONSABILIDAD CIVIL ENTRE CÓNYUGES EN EL DERECHO FRANCÉS CONTEMPORÁNEO*
}

[Liability between spouses in modern French Law]

\section{Mauricio TAPIA R.**}

\section{RESUMEN}

El artículo examina los dos estatutos de responsabilidad civil del derecho francés, aplicables entre cónyuges. Se refieren tanto a los daños que provienen de los hechos que motivan el divorcio como aquellos generados por la disolución del matrimonio. El primero se funda en el derecho común de la responsabilidad por culpa; el segundo, en el régimen especial del artículo 266 del Código Civil, sin culpa y sujeto a la prueba de "consecuencias de una particular gravedad”. El estudio analiza críticamente la naturaleza de esos regímenes, su asimetría y su aplicación práctica por la jurisprudencia reciente.

\section{ABSTRACT}

This article examines both legal regimes of civil liability of the French Law, which are enforceable between spouses. They refer as to damages arising from issues in which divorce is founded, as to those coming from the dissolution of marriage. The first one arises from common legislation about guilt-based liability, the second one, in the special regimen of the art. 266 of Code, with no consideration to guilt and based on the proof of "particularly severe consequences". The contribution analyzes critically the character of both regimes, their asymmetry and practical application by the courts.

RECIBIDO el 27 de marzo de 2017 y APROBADO el 5 de mayo de 2017

* Este artículo se enmarca en el Proyecto Fondecyt 1150 711, "Los daños en el divorcio frente al sistema general de responsabilidad civil", en el que el autor es coinvestigador.

** Profesor de derecho civil de la Universidad de Chile (mtapia@derecho.uchile.cl). 
Se concluye que, ante todo, se trata de dos regímenes completamente excepcionales, que sólo permiten conceder indemnizaciones en casos muy justificados (culpas calificadas o daños muy graves), las que, en todo caso, son sistemáticamente muy bajas.

\section{Palabras Clave \\ Divorcio - Responsabilidad civil - Derecho francés}

The conclusion is that these are two exceptional regimes, which allow to grant reparation in justified and systematically few cases (severe guilt or damages).

KeyWORDS Law.

\section{INTRODUCCIÓN}

En materia de daños entre cónyuges en el derecho francés han coexistido durante décadas dos estatutos. Por una parte, se encuentra el que proviene del régimen general del derecho común, relativo a la responsabilidad extracontractual por culpa, contenido en el artículo 1382 del Código Civil, al que se sujetan todos los daños entre cónyuges provocados por los hechos que dan lugar al divorcio, en particular, cuando se vulneran otros bienes jurídicos protegidos por el ordenamiento, distintos a la mera infracción de deberes conyugales, como la integridad física o psíquica y la honra. Y, por otra parte, el que se funda en el artículo 266 del mismo Código, relativo a los perjuicios de una "particular gravedad" que provoca la disolución del matrimonio en sí mismo, y que prescinde de la culpa.

En teoría - ya veremos que en la práctica la distinción no es tan nítida y pacífica -, el primer régimen repara los daños causados por los hechos que dan lugar al divorcio, en cambio, el segundo, permite indemnizar ciertos perjuicios particularmente "graves" que provoca la disolución del vínculo propiamente tal ${ }^{1}$.

En efecto, aunque la distinción entre ambos estatutos parece simple, en la práctica está lejos de serlo, y ha provocado un contencioso errático y confuso, y asimetrías en las condiciones exigidas para acceder a la indemnización.

Por una parte, bajo el estatuto general se indemnizan los daños provenientes de sucesos graves ocurridos durante el matrimonio y que justifican el divorcio por culpa, tales como un adulterio con ribetes escandalosos o

1 Vid. sobre esta distinción: CARBOnNIER, Jean, Droit civil. Introduction. Les personnes. La famille, l'enfant, le couple (París, Quadrige/PUF, 2004), pp. 1355 y ss. 
la violencia entre cónyuges. La indemnización sólo es procedente cuando el matrimonio se disuelve por divorcio por culpa exclusiva de un cónyuge y debe solicitarse en conjunto con éste y no después. Por estar sujeto al estatuto general de responsabilidad, es necesario acreditar la "culpa" del cónyuge, cuestión que, además de envolver una complejidad adicional, expone a la ventilación de intimidades ante los jueces, lo que evidentemente no facilita la "pacificación" de la formalización del término de la relación ${ }^{2}$. Asimismo, aunque ese estatuto general sólo exige una simple culpa (leve), en la práctica la jurisprudencia no se contenta con ello, y exige la demostración de una culpa "calificada", lo que según muchos esconde una convicción, no declarada, de que el divorcio por culpa envuelve en sí mismo ya una sanción y que sólo las faltas particularmente graves pueden agregar una segunda, esto es, la indemnización de perjuicios. Esto lleva a que las condenas sean excepcionales y que los montos otorgados sean exiguos $^{3}$.

Por otra parte, bajo el estatuto especial, y según la redacción de la norma otorgada por la reforma del divorcio del año 2004, no resulta en principio necesario acreditar la culpa (es, según algunos autores, una responsabilidad estricta), pero sí debe probarse que la disolución del vínculo haya provocado

${ }^{2}$ Vid. respecto de la función "pacificadora" de las leyes de divorcio, en Francia: Carbonnier, Jean, Le divorce, en Essais sur les lois (París, Répertoire du Notariat Defrénois, 1995, 2a ed.), pp. 131-167; y, para el caso chileno: TAPIA, Mauricio, Nulidad y divorcio en el proyecto de nueva Ley de Matrimonio civil, en Revista Estudios Públicos 86 (2002), pp. 223-245.

${ }^{3}$ Así se desprende, ante todo, de los numerosos fallos analizados en este artículo. A mayor abundamiento, en un completo balance de la jurisprudencia francesa sobre la materia, efectuado por la revista Droit de la famille sobre el universo de fallos dictados por la Corte de Casación, en un período de 10 años, desde la reforma de 2004, se concluye lo siguiente: a) Que los fallos dictados por esa Corte, sobre la base de este artículo 1382 del Código Civil, ascienden a 21; y, b) Que tales fallos condenan en sumas que no exceden los 15 mil euros. Por su parte, en el mismo balance, de 100 fallos de apelación analizados (firmes y ejecutoriados), representativos de 30 Cortes de Apelaciones (tanto sobre el fundamento del artículo 1382 como del artículo 266 del Código Civil), se concluye que, cuando la demandante de la indemnización es la mujer: El $52 \%$ de los fallos condenan a sumas inferiores a 3.000 euros, el $29 \%$ a sumas de entre 3.000 y 5.000 euros, el $15 \%$ a sumas de entre 5.000 y 15.000 euros, y el $4 \%$ a sumas de entre 15.000 y 20.000 euros. En las hipótesis en que el demandante de la indemnización es el hombre: el $82 \%$ de los fallos conceden sumas inferiores a 3.000 euros y el 18\% restante a sumas de entre 3.000 y 5.000 euros. Vid. SCHOUflikir, Anaïs (coord.), Dossier: Les dommages et intérets entre époux, en Droit de Famille 7 y 8 (2015), pp. 13 y ss.; y, LAFON, Catherine, Panorama de jurisprudence. Dommages- intérêts entre époux dans les décisions de cours d'appel, en Droit de Famille 7 y 8 (2015), pp. 26 y ss. 
al demandante "consecuencias de una particular gravedad". Esta noción, que no tiene equivalentes en el derecho de la responsabilidad civil en Francia, ha sido muy difícil de discernir por los tribunales, al punto que la Corte de Casación rara vez la ha aceptado, incluso en circunstancias particularmente gravosas para el demandante, otorgando incluso montos más exiguos que bajo el primer estatuto ${ }^{4}$.

Estas mismas circunstancias hacen que el ejercicio profesional en la materia sea confuso y difícil, siendo usual que las demandas califiquen erróneamente el estatuto al que se sujetan los daños que se esgrimen, equivocaciones que también en ocasiones se transmiten a las decisiones de justicia.

Es por estos motivos que, como se expondrá, una parte importante de la doctrina insta en el presente a un cambio legal que pueda unificar estos estatutos y disipar estas ambigüedades y asimetrías.

Para analizar estas materias, este artículo se divide en dos secciones: en la primera (II), se analizará la indemnización de daños entre cónyuges a la luz del estatuto del derecho común; y, en la segunda (III), la indemnización de daños entre cónyuges conforme al estatuto especial del artículo 266 del Código Civil.

\section{INDEMNIZACIÓN DE DAÑOS ENTRE CÓNYUGES CONFORME} AL RÉGIMEN DE DERECHO COMÚN (ARTÍCULO 1382 DEL

\section{Código Civil)}

El régimen de responsabilidad civil extracontractual en Francia está estructurado sobre una amplísima "cláusula general "fundada en la culpa (leve) $)^{5}$. Habiendo recibido el impulso del racionalismo (particularmente

${ }^{4}$ En efecto, desde la reforma de este artículo en el año 2004 sólo existe un fallo de la Corte de Casación que concede la reparación sobre la base de este artículo 266 del Código Civil. Me refiero al fallo de la Corte de Casación, 1a Sala Civil, de 12 de septiembre de 2012, No11-12.140. En cuanto al número de fallos de apelación pronunciados sobre la base de este artículo 266, en relación a aquellos dictados sobre el fundamento del artículo 1382 del Código Civil, la proporción es la siguiente: cuando la demandante de la indemnización es la mujer, un 19\% de los fallos se ha fundado en el artículo 266, un 75\% sobre el artículo 1382 y el $6 \%$ restante no lo precisa; $y$, cuando el demandante de la indemnización es el hombre, un $9 \%$ se ha fundado en el artículo 266, un $82 \%$ en el artículo 1382 y el $9 \%$ restante no lo precisa. Vid. Lafon, Catherine, ibidem, pp. 26 y ss.

${ }^{5}$ Respecto del origen y alcance de esta regla del artículo 1382 del Código Civil francés, vid. VINEY, Geneviève, Introduction à la responsabilité (París, L.G.D.J., 2008, $3^{\mathrm{a}}$ ed.), pp. 20 y ss.; y, TAPIA, Mauricio, Código Civil. 1855-2005. Evolución y perspectivas (Santiago, Editorial Jurídica de Chile, 2005), pp. 274 y ss. 
de Grocio), esta formulación de un principio general de responsabilidad por culpa es propia de ese mismo espíritu de abstracción y generalidad que dio también nacimiento a la noción actual de contrato. La verdadera innovación es la generalidad de la fórmula empleada y no la culpa o negligencia, que como criterio de atribución de la responsabilidad civil por algunos ilícitos específicos ya estaba presente en Roma. Recibiendo una formulación jurídica en las obras de Domat y Pothier, esta regla general fue recogida solemnemente en la fórmula del artículo 1382 del Código Civil francés: "Todo hecho cualquiera del hombre, que causa daño a otro, obliga a quien por cuya culpa ocurrió a repararlo"6.

Esta norma dotó a los jueces de una útil herramienta para expandir la responsabilidad civil a nuevos ámbitos, al exigir simplemente la prueba de una culpa, un daño y una relación de causalidad, no importando el área de actividad en que ello ocurriera. En el siglo XX, por lo demás, la jurisprudencia francesa perfeccionó un juicio de culpabilidad objetivo, sobre la base del patrón abstracto del "buen padre de familia", prescindiendo de subjetividades, cuestión que nuevamente significó un impulso a la expansión de la responsabilidad civil ${ }^{7}$. Al mismo tiempo, el daño, particularmente el moral, fue también expandiendo sus límites, tanto en los bienes que protege (por ejemplo, los derechos de la personalidad) como en las categorías que comprende internamente (precio del dolor, perjuicio de agrado, perjuicio estético, perjuicio sexual, etc. $)^{8}$.

Expuesto de esa forma, la conclusión evidente es que el estatuto de responsabilidad civil extracontractual francés permite a los jueces, en teoría, una amplia indemnización de daños provocados entre cónyuges durante el matrimonio y por los hechos que dan lugar al divorcio, sobre la base de cualquier comportamiento culpable unido en relación de causalidad con aquéllos. Recordemos que el artículo 266 del Código Civil establece la

${ }^{6}$ La numeración de este artículo cambió el año 2016. Actualmente corresponde al artículo 1240 del Código Civil francés, cuyo texto es idéntico al antiguo artículo 1382. En efecto, la reforma del derecho de los contratos, del régimen general y de la prueba de las obligaciones (Ordenanza No2016-131, de 10 de febrero de 2016, que entró en vigor el $1^{\circ}$ de octubre de 2016) modificó la numeración de varios títulos del Libro III, pero sin alterar el contenido de las normas relativas a la responsabilidad civil. Éstas serán objeto de otra reforma, cuyo proceso se inició con el anteproyecto publicado por el Ministerio de Justicia, el 29 de abril de 2016, que se encuentra en etapa de consulta y discusión.

${ }^{7}$ Sobre esta evolución de la culpa en el derecho francés puede consultarse la brillante exposición y síntesis del querido y recordado profesor CHABAS, François, Cien años de responsabilidad civil en Francia (París, van Dieren, 2004 traducción y notas de Mauricio TAPIA), pp. 23 y ss.

${ }^{8}$ Ibidem, pp. 75 s. 
hipótesis de daños de una particular gravedad producto de la disolución, siendo, en cambio, el estatuto general el aplicable únicamente a los daños ocurridos antes de ese suceso y por los hechos que dan lugar al divorcio culpable?. Esto es, sólo procede en hipótesis de divorcio por culpa exclusiva de un cónyuge.

No obstante, en la práctica, la jurisprudencia francesa aplica de forma muy restrictiva este régimen en la materia y, cuando da lugar a la indemnización, se trata, en general, de hipótesis muy calificadas, y los montos de la reparación son, en todo caso, sistemáticamente bajos ${ }^{10}$.

La siguiente exposición resume las conclusiones que pueden extraerse en la materia de la revisión de las sentencias de la Corte de Casación y de las Cortes de Apelaciones:

a) En primer lugar, como lo afirmaba Jean Carbonnier, resulta curioso constatar que en este caso se trata de hipótesis de responsabilidad que ocurren durante la vigencia del contrato matrimonial y que, no obstante, se abordan con las reglas de la responsabilidad civil extracontractual. Como señalaba Jean Carbonnier: “¿Por qué, sin embargo, razonar sobre la base de la responsabilidad delictual? La indemnización de perjuicios se podría concebir perfectamente sobre la base de una resolución abusiva del matrimonio-contrato" ${ }^{11}$. En gran medida ello se debe a que los casos inciden en la vulneración de bienes jurídicos independientes de los simples deberes conyugales, tales como la honra o la integridad física o psíquica.

b) En segundo lugar, existen innumerables fallos que rechazan la indemnización de daños por este concepto. Este elevado número de rechazos, "anormal" según un estudio reciente, se explica en la idea de que, usualmente, "las culpas alegadas son el corolario normal y lógico, aunque ello sea triste, de una demanda de divorcio"12. Como lo ha señalado este mismo autor, "lo que sucede es que muchos jueces de fondo aceptan con cierto fatalismo que este tipo de excesos [se refiere incluso a violencias conyugales o humillaciones públicas producto de un adulterio] son una consecuencia lógica del divorcio"13.

En gran medida esto se explica porque los jueces de fondo estiman que un divorcio pronunciado sobre la base de la culpa exclusiva de uno

9 Sobre esta distinción, vid. KeSSLER, Guillaume, Les dommages et intérêts dans le divorce: panorama de jurisprudence en Droit de la famille 7 y 8 (2015), pp. 19 y ss.

${ }^{10}$ En efecto, así se desprende de los fallos analizados en esta sección y se confirma por las estadísticas mencionadas, cit. (n. 5).

${ }^{11}$ Carbonnier, Jean, cit. (n. 3), p. 1371.

12 CASEY, Jérôme, Articles 1382 et 266 du Code civil. Analyse de jurisprudence et synthèse en Droit de la famille 7 y 8 (2015), pp. 14 y ss.

${ }^{13}$ Ibidem. 
de los cónyuges, envuelve en sí mismo una suficiente "sanción". Por ello, la Corte de Casación también insiste en que el objeto propio del divorcio no es reparar un perjuicio. En efecto, lo que permiten concluir muchas decisiones, es que la Corte de Casación estima que la culpa que da lugar al divorcio (o que es suficiente para pronunciarlo), no constituye per se la culpa que da lugar a la reparación sobre la base del artículo 1382 del Código Civil ${ }^{14}$.

Asimismo, esta reticencia se vincula a la existencia, en muchos casos, de culpas compartidas, cuestión que generalmente conduce al rechazo de la demanda de indemnización planteada por uno de los cónyuges ( $\mathrm{y}$ no a la reducción de la indemnización ${ }^{15}$.

No obstante, al mismo tiempo, la Corte de Casación ha declarado insistentemente que una demanda de divorcio, por culpa exclusiva de uno de los cónyuges, puede dar lugar, en teoría, a esta reparación, tal como lo concluyó claramente en un importante fallo de 12 de junio de $2013^{16}$. En efecto, como lo demuestra la revisión de las decisiones judiciales de la última década, puede dar lugar a la reparación, pero en casos muy excepcionales y calificados, tal como se expone a continuación.

c) En tercer lugar, efectivamente es posible encontrar decisiones judiciales que conceden una indemnización, bajo el amparo del artículo 1382 del Código Civil, pero, a diferencia de lo que ocurre en casos ordinarios de responsabilidad extracontractual, los jueces la otorgan sólo cuando la culpa en cierta forma es "calificada".

Recordemos que sobre la base de este artículo se pueden reparar los daños provocados por hechos anteriores a la ruptura, aun cuando sean éstos los que justifican o provocan en definitiva el divorcio por culpa ${ }^{17}$.

Ahora bien, debe tenerse en cuenta que el artículo 242 del Código Civil, que establece el divorcio por culpa, prescribe que el mismo puede demandarse frente una violación "grave" o "reiterada" de deberes matrimoniales, que vuelvan "intolerable la mantención de la vida en común”.

${ }^{14}$ Ibidem. Ello también explica por qué la Corte de Casación rechaza reducir la indemnización (en los casos en que se concede) en razón de que el divorcio se ha concedido por "culpas compartidas", pues ello envuelve confundir la culpa como causal de divorcio con la culpa como fuente de responsabilidad (o, en este caso, como justificación para disminuir la reparación, en razón de la "culpa de la víctima"). Vid. Corte de Casación, 1 a Sala Civil, 12 de enero de 2011, No09-15.426.

15 Ibidem.

${ }^{16}$ Corte de Casación, 1a Sala Civil, 12 de junio de 2013, No12-18.211. En este sentido, existen innumerables fallos anteriores. Por ejemplo, de la misma Sala: 23 de mayo de 2012, No11-16.964; 18 de enero de 2012, No11-10.959; y, $1^{\circ}$ de junio de 2011, No10-17.461.

${ }^{17}$ KessLer, Guillaume, cit. (n. 11), p. 21. 
Por su parte, la culpa del artículo 1382, para dar lugar a la reparación, no necesita ser grave o reiterada, ni volver intolerable la vida en común.

No obstante, en la práctica, rara vez los jueces se contentan con una culpa simple, y exigen la constatación de una culpa calificada, e incluso cuando se prueba una negligencia de esta naturaleza ello no envuelve una garantía que se condene a la reparación ${ }^{18}$. En síntesis, los jueces son extremadamente exigentes para conceder una indemnización entre cónyuges bajo este estatuto porque, como se dijo, subyace en ellos una cierta convicción de que el divorcio pronunciado por culpa ya envuelve en sí mismo una especie de sanción.

Algunos ejemplos pueden ser útiles para demostrar esta posición reticente de la jurisprudencia.

Ante todo, en materia de adulterio, que es una de las hipótesis más discutidas en el derecho francés como en otros sistemas ${ }^{19}$. Un adulterio grave o reiterado, que vuelve intolerable la vida en común, sistemáticamente da lugar a la demanda de divorcio, pero no ocurre lo mismo tratándose de la indemnización de daños que el cónyuge "inocente" asocie a la misma. Así, por ejemplo, el abandono de parte del marido para vivir en concubinato con una amiga del colegio en la casa familiar, no da lugar a tal reparación ${ }^{20}$. Así también, un adulterio cometido por una mujer con su superior jerárquico, y habiéndose probado que privilegió esa relación en detrimento de su cónyuge y de sus hijos, no justifica el otorgamiento de una indemnización, por cuanto ello no excede la situación habitual de una persona que se encuentra en la misma posición ${ }^{21}$. En efecto, como ha señalado recientemente un autor, "para justificar el pago de una indemnización de perjuicios, el adulterio debe venir acompañado con otra falta o revestir un grado de gravedad que lo distinga de la relación extraconyugal 'clásica"”22.

Por ejemplo, los siguientes casos con considerados por la jurisprudencia (decisiones de Cortes de Apelaciones) como suficientemente graves para dar lugar a la reparación: el llevar una "doble vida" con otra pareja durante

18 Ibidem.

19 En Francia, KessLer, Guillaume, cit. (n. 11), p. 21. También en el sistema chileno: TAPIA, Mauricio, Divorcio y responsabilidad civil en el derecho chileno en Revista de Derecho Universidad de Concepción 239 (2016), pp. 152 y ss.

${ }^{20}$ Corte de Apelaciones de Poitiers, 4a Sala Civil, 25 de febrero de 2015, No14/01081.

${ }^{21}$ Corte de Apelaciones de Bourges, Sala Civil, 5 de marzo de 2015, No14/00781.

22 En Francia, KessLer, Guillaume, cit. (n. 11), p. 21. 
años ${ }^{23}$; el gran número de relaciones "libertinas" de la mujer ${ }^{24}$; el comportamiento del marido en orden a jactarse de haber mantenido relaciones sexuales sin protección con prostitutas contactadas por internet ${ }^{25}$; cuando el adulterio conduce al nacimiento de diversos hijos de mujeres distintas ${ }^{26}$, entre otras. Por otra parte, como sostiene Guillaume Kessler, usualmente los tribunales también consideran como una culpa suficientemente grave para dar lugar a la reparación la circunstancia de que el adulterio sea expuesto amplia y públicamente por quien incurre en el mismo, como cuando la esposa mantiene una relación con un amigo de la familia, quien la presenta además a sus conocidos como su pareja, o cuando la relación es difundida públicamente por las redes sociales, como facebook ${ }^{27}$.

Más allá del adulterio, la indemnización de perjuicios, sobre la base del artículo 1382 del Código Civil, se tiende a conceder también cuando se afecta a otros bienes jurídicos protegidos, configurando así una culpa calificada. Así ocurre, por ejemplo, cuando los hechos que motivan la ruptura dejan en completa indefensión material al cónyuge y a los hijos, como cuando el marido no respeta un derecho de uso del inmueble familiar asignado a la mujer, viéndose ésta en la necesidad en incurrir en elevados gastos para arrendar un inmueble para ella y los hijos ${ }^{28}$; cuando el marido abandona a la mujer con su hijo, siendo ella extranjera, no contando con visa y $\sin$ dinero $^{29}$; o cuando la ruptura va acompañada de violencia grave ${ }^{30}$.

Se trata en estos casos, como se entiende, de la protección de otros bienes jurídicos tutelados por el ordenamiento, como la integridad física o psíquica, la honra o, incluso, el deber de sustentar económicamente a la familia común. Aquí se presenta un punto de encuentro con la jurispru-

${ }^{23}$ Corte de Apelaciones de Reims, 1a Sala Civil, sección 2, 16 de enero de 2015, No14/00022.

${ }^{24}$ Corte de Apelaciones de Toulouse, $1^{a}$ Sala, sección 2, 3 de marzo de 2015, No $13 / 05591$.

${ }^{25}$ Corte de Apelaciones de Versailles, 2a Sala, sección 2, 15 de enero de 2015, No13/04231.

${ }^{26}$ Corte de Apelaciones de Poitiers, 4a Sala Civil, 25 de febrero de 2015, No14/01000.

${ }^{27}$ Kessler, Guillaume, cit. (n. 11), p. 21. Estos casos fueron fallados por: Corte de Apelaciones de Versailles, 2a Sala, sección 1, 29 de enero de 2015, No13/09445; y, Corte de Apelaciones de Limoges, Sala Civil, 30 de marzo de 2015, No14/00458, respectivamente.

${ }^{28}$ Corte de Apelaciones de Toulouse, 1a Sala, sección 2, 8 de abril de 2015, No14/00975.

${ }^{29}$ Corte de Apelaciones de Lyon, 2a Sala, sección B, 3 de marzo de 2015, No14/01392.

${ }^{30}$ Corte de Apelaciones de París, 3a Sala, 9 de abril de 2015, No13/18059. 
dencia chilena, que concede indemnización en estos casos no por el mero incumplimiento de deberes conyugales, sino que por una ruptura que se acompaña de la vulneración de esos otros bienes jurídicos protegidos ${ }^{31}$.

Más allá, en este panorama de la jurisprudencia francesa sobre la base del artículo 1382 del Código Civil, existen también decisiones simplemente sorprendentes y que han sido fuertemente criticadas por la doctrina. Es el caso, en particular, del fallo de 3 de mayo de 2011, de la Corte de Apelaciones de Aix-en-Provence, que concedió, junto con el divorcio por culpa exclusiva de su cónyuge, una indemnización de perjuicios a un mujer en razón de la abstinencia (pero con algunos intervalos) de relaciones sexuales durante varios años, siendo que el marido no justificó tener problemas de salud que las imposibilitaran. En este curioso y criticable caso, esa Corte de Apelaciones termina concluyendo que "las relaciones sexuales entre cónyuges son, en particular, la expresión de la afección que ellos se tienen mutuamente, al mismo tiempo de inscribirse en la continuidad de deberes que derivan del matrimonio" 32 . En primer lugar, como lo han señalado algunos autores en Francia, los deberes conyugales de fidelidad (artículo 212 del Código Civil) y de comunidad de vida (artículo 215 del Código

${ }^{31}$ En el derecho chileno, han concluido en este sentido, esto es, que la indemnización procede en caso de divorcio en la jurisprudencia nacional, en esencia, cuando se vulneran otros bienes jurídicos protegidos, los siguientes autores: SEVERIN FUSTER, Gonzalo, Indemnización entre cónyuges por los daños causados con ocasión del divorcio, en GuZMÁn Brito, Alejandro (ed.), Estudios de Derecho Civil III. Jornadas nacionales de derecho civil, Valparaíso, 2007 (Santiago, LegalPublishing, 2008), pp. 99-140; y, ETCHEBERry COURT, Leonor, Responsabilidad civil ante el quebrantamiento del deber de fidelidad entre los cónyuges. Corte Suprema, 13 de junio de 2012, comentario de jurisprudencia, en Revista chilena de derecho privado 19 (2012), pp. 215-218. Al respecto, el autor de este artículo ha tenido oportunidad de referirse a la improcedencia de la responsabilidad civil por el mero incumplimiento de deberes conyugales en la jurisprudencia chilena y, en cambio, a su procedencia cuando se vulneran otros bienes jurídicos protegidos, en: TAPIA, Mauricio, Aproximación crítica a la indemnización de perjuicios por incumplimiento de deberes conyugales en VIDAL Álvaro, SEVERIN Gonzalo y MejÍAs Claudia (coord.), Estudios de Derecho Civil X, Jornadas nacionales de derecho civil, Valparaiso 2014 (Santiago, LegalPublishing-Thomson Reuters, 2015), pp. 231-247; TAPIA, Mauricio, Contra la indemnización de perjuicios por incumplimiento de deberes conyugales, en Lepín, Cristián y GOMEz De LA Torre, Maricruz (coord.), Estudios de derecho familiar I. Actas primeras jornadas nacionales. Facultad de Derecho Universidad de Chile (Santiago, Thomson Reuters, 2016), pp. 163-179; TAPIA, Mauricio, El incumplimiento de deberes conyugales no da lugar a la indemnización de perjuicios (Corte Suprema, 30 de diciembre de 2014) en Revista de Estudios Judiciales 2 y 3 (2016), pp. 137-144; y, TAPIA, Mauricio, Divorcio, cit. (n. 21).

32 Corte de Apelaciones de Aix-en-Provence, 6a Sala, 3 de mayo de 2011, No09/05752. 
Civil) no obligan, en caso alguno, a la mantención de relaciones sexuales ni menos a una determinada periodicidad en las mismas. En ese sentido, por tanto, el fallo es claramente contrario a derecho. Por otra parte, sostener lo que afirma este fallo envuelve un claro atentado a la libertad sexual, además de representar una intromisión inaceptable en la intimidad de las personas. Afortunadamente, se trata de decisiones aisladas y fuertemente resistidas y criticadas $^{33}$.

d) Finalmente, debe destacarse que las decisiones que, en carácter de excepcionales como se ha expuesto, conceden indemnización de perjuicios sobre la base de este artículo 1382 del Código Civil, otorgan sumas bastante bajas, entre los 3.000 y 20.000 euros $^{34}$. Nuevamente, esto muestra la percepción de los jueces en orden a que el divorcio pronunciado por culpa de uno de los cónyuges envuelve en sí mismo una especie de sanción, y de ahí la reticencia a conceder además una indemnización.

\section{INDEMNIZACIÓN DE DAÑOS ENTRE CÓNYUGES CONFORME AL RÉGIMEN ESPECIAL POR "CONSECUENCIAS DE UNA PARTICULAR GRAVEDAD” PROVOCADAS POR LA DISOLUCIÓN (artículo 266 del Código Civil)}

Como ya se adelantó, el artículo 266 del Código Civil permite exigir la reparación únicamente de los perjuicios provocados "por la ruptura del vínculo conyugal", y no por los hechos que fundan el divorcio, y bajo la condición de que ellos sean de una "particular gravedad". El texto de esta norma, según la reforma de la Ley No2004-439, de 26 de mayo de 2004, prescribe lo siguiente: "Sin perjuicio de la aplicación del artículo 270 , una indemnización de perjuicios puede ser concedida a un cónyuge como reparación de las consecuencias de una particular gravedad que sufra por el hecho de la disolución del matrimonio, ya sea cuando él ha sido demandado en un divorcio pronunciado por alteración definitiva del vínculo conyugal, y que él mismo no haya planteado ninguna demanda de divorcio, ya sea cuando el divorcio ha sido pronunciado por la culpa exclusiva de su cónyuge. Esta demanda no puede ser planteada sino con ocasión de la acción de divorcio".

En la materia, la reforma de 2004 quiso de cierta manera "pacificar" el

${ }^{33}$ Una visión crítica en: Pierroux, Emmanuèle, En mariage, ton époux tu honoreras! en Gazette du Palais, 23-24 (2011), pp. 9 y ss. También: Pizarro, Laura, L'épouse créancière de dommages et intérêts pour abstinence sexuelle préjudiciable en La Semaine Juridique, Édition Générale 43-44 (2011), pp. 1925 y ss.

${ }^{34}$ Vid. al respecto CaSEY, Jérôme, cit. (n. 14), p. 18. Vid. también estadísticas en cit. (n. 5). 
divorcio, "disociando la culpa y el dinero", modificando la regla anterior (proveniente de una ley de 1975) que permitía demandar daños morales y patrimoniales provocados únicamente por la culpa exclusiva y probada del cónyuge que ha dado lugar al divorcio ${ }^{35}$. En efecto, el artículo 266 del Código Civil, en la redacción anterior proveniente de la Ley de 11 de julio de 1975, disponía lo siguiente: "Cuando el divorcio es pronunciado por culpa exclusiva de uno de los cónyuges, éste puede ser condenado a la indemnización de perjuicios en reparación del daño patrimonial o moral que la disolución del matrimonio genera a su cónyuge. Este último no puede demandar la indemnización de perjuicios sino que con ocasión de la acción de divorcio".

Esta regla de 1975, que recoge en parte una norma introducida en 1941 y en 1945 en el Código Civil, suponía dos condiciones para su aplicación: de un lado, que el divorcio haya sido pronunciado sobre la base del artículo 242 del Código Civil, por culpa exclusiva del cónyuge que causó el perjuicio (excluyendo otras causales de divorcio, a diferencia de la redacción actual de la norma); y, que la demanda de indemnización de perjuicios sea planteada en el juicio de divorcio y no después, cuestión que es consistente con el principio introducido por la ley de 1975 en orden a concentrar el conocimiento y resolución de todas las consecuencias del divorcio en un solo contencioso ${ }^{36}$.

Por lo demás, la norma, en su redacción de 1975, asociaba claramente la acción de indemnización a la "culpa" exclusiva del cónyuge que provocaba el daño (y no procedía en otra causal de divorcio), y es por ello que algunos autores afirmaban, como el célebre Jean Carbonnier, que esta indemnización de perjuicios funcionaba en realidad como "una pena privada, tendiente a sancionar no el divorcio, sino los comportamientos que lo provocaron" ${ }^{37}$. De ahí que, sobre la base de esa redacción haya podido también sostenerse que si lo que se "sancionaba" con la indemnización (sin entrar en el debate si la indemnización puede ser considerada como una "pena privada", cuestión que es propia de otra discusión) $)^{38}$ eran en realidad los comportamientos que generaron el divorcio, la regla no era

35 Vid. Piwnica, Dominique, Les dommages et intérêts de l'article 266 du Code civil dans la loi du 26 mai 2004 en La Semaine Juridique, Édition Générale 45 (2009), pp. 44-45.

36 Carbonnier, Jean, cit. (n. 3), p. 1355.

${ }^{37}$ Ibidem, p. 1356.

38 Vid. al respecto, en Francia: CARVAL, Suzanne, La responsabilité civile dans sa fonction de peine privée (París, LGDJ, 1995). 
entonces más que una repetición o una aplicación especial del artículo 1382 del Código Civil, ya analizado más arriba en este estudio ${ }^{39}$.

$\mathrm{Y}$, en realidad, así parecía serlo, pues tampoco la regla exigía que los daños provocados tuvieran una cierta "calificación" o "gravedad". La redacción de 1975 sólo apelaba a la culpa y declaraba indemnizables los daños patrimoniales y morales, tal como sucede si se invoca el artículo $1382 \mathrm{del}$ Código Civil. En cuanto a los daños patrimoniales, se sostenía que ellos usualmente quedaban reparados por la "prestación compensatoria" del artículo 270 del Código Civil (equivalente a la compensación económica del derecho chileno), aunque se afirmaba que, al menos en teoría, podían surgir otros daños patrimoniales indemnizables bajo este rótulo como, por ejemplo, los gastos excesivos que exija el cambio del domicilio conyugal. En cuanto al daño moral, la situación no era distinta de aquella que podía plantearse sobre la base del artículo 1382 del Código Civil ${ }^{40}$.

Sin duda que el artículo aludía claramente a los daños provocados por la "disolución del matrimonio", pero en la práctica ellos se confundían fácilmente con los provocados por los hechos culpables que provocaban la disolución, configurándose, en realidad, como una norma que no se distinguía en la práctica de los resultados que se podían obtener invocando al estatuto general de la responsabilidad civil extracontractual. En realidad, la jurisprudencia en la materia daba prueba más bien de una práctica vacilante, por ejemplo, rechazaba la demanda cuando no se justificaba de forma precisa cómo el daño provenía de la disolución del vínculo (en este caso, abandono de la casa familiar por la mujer, dejándole al marido todas las tareas del hogar) ${ }^{41}$, pero en otras oportunidades daba lugar a la reparación por hechos que inequívocamente provenían de circunstancias anteriores a la disolución y no provocadas directamente por ésta (como la separación ocurrida después de un largo período de vida en común ${ }^{42}$.

Por esta misma circunstancia, el contencioso era también formalista y complejo, y así la Corte de Casación rechazaba la indemnización cuando no se invocaba ningún estatuto de responsabilidad civil o impedía aplicar un estatuto no invocado, cuestión que convertía la elección del régimen en un aspecto estratégico esencial (y tal decisión no era fácil, por las

39 Vid. en este sentido: Carbonnier, Jean, cit. (n. 3), p. 1371; y, Pons, Stéphanie, La réception par le droit de la famille de l'article 1382 du Code civil, (Aix-enProvence, PUAM, 2007), p. 175.

${ }^{40}$ Carbonnier, Jean, cit. (n. 3), pp. 1355 y 1356.

${ }^{41}$ Corte de Casación, 2a Sala Civil, 31 de mayo de 1995, en Dalloz, 1996, p. 424.

${ }^{42}$ Corte de Casación, 2a Sala Civil, 27 de enero de 2000, en Revue trimestrielle de droit civil, 2000, p. 300. 
proximidades de ambos estatutos) ${ }^{43}$. Como se entiende, se trataba de un sistema difícil de discernir incluso para los expertos, por la circunstancia que envolvía un doble estatuto en gran medida innecesario, repetitivo o al menos insuficientemente diferenciado.

Lamentablemente, la reforma de 2004, que pretendió en parte poner fin a esa confusión, en la práctica no lo logró.

En efecto, el actual artículo 266 del Código Civil francés, luego de la reforma de 2004 (Ley No2004-439), establece que puede otorgarse una indemnización por las "consecuencias de una particular gravedad" que sufra un cónyuge por la disolución del matrimonio, tanto en el caso de divorcio por alteración definitiva del vínculo conyugal como en el caso de divorcio debido a la culpa exclusiva de un cónyuge.

En relación a la redacción anterior, ésta norma presenta las siguientes particularidades:

a) En primer lugar, a diferencia de la anterior, esta nueva regla parte por señalar que la indemnización que regula es "sin perjuicio de la aplicación del artículo 270" del Código Civil, esto es, sin perjuicio de la prestación compensatoria que sea procedente. La innovación es relativa, pues la jurisprudencia ya había concluido, sobre la base de la anterior norma, que la prestación compensatoria era independiente de la indemnización y que la primera no podía perseguir la segunda ${ }^{44}$. Se trata, en consecuencia, como se denomina en Francia, de una codificación de un "aporte" consolidado de la jurisprudencia, cuestión que recientemente se realizó en el Código Civil francés, en una escala mayor, en materia de contratos y obligaciones ${ }^{45}$.

b) En segundo lugar, abre la posibilidad de la reparación no sólo para el caso de divorcio culpable, sino también para el declarado por alteración definitiva del vínculo conyugal (artículos 237 y 238 del Código Civil). Una idea similar ya se había planteado en la discusión de la ley de 1975, en orden a aplicarla al divorcio por ruptura de la vida en común, pero la proposición fue rechazada porque se consideró que cuando un cónyuge solicita el divorcio por cese de la vida en común, no podía invocar tal causal como una causa legítima de divorcio y, al mismo tiempo, como una "culpa" generadora de indemnización de perjuicios ${ }^{46}$. El rechazo, en ese

${ }^{43}$ Corte de Casación, 2a Sala Civil, 8 de junio de 1995, en Revue trimestrielle de droit civil,1995, p. 869.

${ }^{44}$ Corte de Casación, 2a Sala Civil, 12 de junio de 1996, en Revue Trimestrielle de Droit Civil,1996, p. 886.

${ }_{45}$ Me refiero a la Reforma del derecho de los contratos, del régimen general y de la prueba de las obligaciones (Ordenanza No2016-131, de 10 de febrero de 2016, que entró en vigor el $1^{\circ}$ de octubre de 2016).

46 Pons, Stéphanie, cit. (n. 41), pp. 175 y 176. 
momento, tenía sentido, pues la posibilidad de indemnización en la ley de 1975 estaba, como se dijo, directamente asociada a la constatación de un comportamiento culpable. Como la nueva ley, en principio, erradica la culpa de la responsabilidad civil, la posibilidad de ampliar las hipótesis de divorcio en que sería procedente se abría sin mayores inconvenientes. Asimismo, la nueva redacción, junto con introducir esta nueva causal, establece la prevención de que el cónyuge que exige la indemnización debe ser el demandado en el juicio de divorcio por alteración definitiva del vínculo conyugal, y siempre que "no haya planteado ninguna demanda de divorcio". En efecto, sería contrario a los "actos propios" el exigir una indemnización por los daños provenientes de una disolución de matrimonio que el mismo demandante, por su parte, ha exigido judicialmente.

c) En tercer lugar, al ampliar las causales de divorcio, no siendo procedente sólo en caso de culpa, se sostiene que esta norma "no trata más de sancionar las culpas conyugales más graves, sino de reparar los perjuicios más severos" ${ }^{47}$. En el mismo sentido se ha sostenido que "esta disposición está menos destinada a sancionar un culpable que a proteger a un inocente" 48 .

No obstante, nuevamente sobre este punto la doctrina no es pacífica. Para algunos, la culpa sigue siendo el fundamento de esta responsabilidad, interpretación que se funda esencialmente en la circunstancia de que procede por divorcio culpable ${ }^{49}$. Para otros, ello envolvería una incoherencia, en atención a que también es aplicable en la otra causal de divorcio, que no exige culpa, y por ello concluyen que "sin decirlo expresamente" el legislador habría introducido una responsabilidad estricta, sin culpa, "para responder al objetivo de protección del cónyuge más débil psicológicamente o del que más valora la unión" ${ }^{50}$. Si consideramos que el espíritu de la reforma de 2004 fue impulsar la "pacificación" del divorcio, parece sensato sostener que esta responsabilidad es objetiva y prescinde de la culpa. En efecto, si ya no existe la posibilidad de obtener una ventaja de la declaración de divorcio por culpa del cónyuge (en términos de prestación compensatoria o de indemnización de perjuicios), entonces ya no existen incentivos para plantear esa demanda, y será más factible, simple y pacífico, divorciarse por causales "objetivas" (como por la causal de

47 Pons, Stéphanie, cit. (n. 41), p. 175.

${ }^{48}$ Garrigue, Jean, Les devoirs conyugaux. Réflexion sur la consistance du lien matrimonial (París, Éditions Panthéon Assas, Thèses, 2012), p. 377.

${ }^{49}$ HAUSER, Jean, Le divorce nouveau et la responsabilité en Droit et patrimoine 136 (2005), p. 78.

${ }^{50}$ Pons, Stéphanie, cit. (n. 41), p. 176. 
alteración definitiva del vínculo conyugal ${ }^{51}$. Sin ir más lejos esta reforma francesa tuvo por propósito original erradicar completamente la culpa en el quiebre matrimonial, eliminando tal causal de divorcio-sanción del Código Civil, objetivo que no fue conseguido por la resistencia de los sectores conservadores que asignan a la "culpa" una función civil similar al "pecado" para la religión ${ }^{52}$.

d) En cuarto lugar, la norma hace referencia, a diferencia del texto anterior, a las consecuencias de una "particular gravedad". La regla, de esta forma, dispone que serán indemnizables daños que no sólo sean "graves", sino de una gravedad singular o particular, mostrando el carácter completamente excepcional que el legislador quiso asignarle a la procedencia de esta acción de responsabilidad.

Así puede leerse en la discusión parlamentaria de esta ley, pues frente a la proposición de un senador de sustituir esta expresión por simplemente "consecuencias graves", el Ministro de Justicia respondió que "la indemnización de perjuicios no constituyen en ningún caso el modo normal de resolver un divorcio", y que ella sólo es legítima cuando se trata de "circunstancias de una particular gravedad", esto es, "una situación excepcional en términos de comportamiento de uno de los cónyuges en relación al otro" ${ }^{53}$.

Como ha señalado con elocuencia un autor, "si no existe una catástrofe, el artículo 266 no es aplicable; él no entra en juego sino cuando la situación es dramática" o, incluso, "indiscutiblemente dramática" ${ }^{54}$.

Tal como se entiende, la norma fue diseñada como una regla de excepción, que pudiera hacer frente a consecuencias totalmente extraordinarias, mucho más allá de las penurias normales que envuelve todo divorcio, tanto en términos materiales (gastos corrientes para establecerse en otro inmueble, etc.) como en consecuencias morales (sufrimientos, etc.).

Si sobre la base del artículo 1382 sólo se reparan, excepcionalmente, los daños provenientes de culpas calificadas y graves (tal como se expuso), conforme a este artículo 266 sólo resultan indemnizables los perjuicios particularmente severos. Ambos estatutos, a fin de cuentas, resultan excepcionales, y de ahí las escasas condenas en la materia.

Así puede concluirse si se analiza la aplicación jurisprudencial de la noción de "consecuencias de una particular gravedad" prevista en este artículo 266, tal como se expone a continuación:

51 Vid. en este sentido Piwnica, Dominique, cit. (n. 37), p. 45.

52 Vid. al respecto, una referencia a los propósitos de esa reforma en: TAPIA, Mauricio, cit. (n. 4), pp. 223-245.

53 Journal officiel de la République française, comptes rendus des débats au Sénat, 2004, pp. 118 y ss.

${ }^{54}$ Garrigue, Jean, cit. (n. 50), p. 377. 
i) La primera cuestión que debe destacarse es que la jurisprudencia ha afirmado que tanto los daños patrimoniales como los daños morales pueden invocarse, al menos en teoría, bajo la condición de que se trate de "consecuencias de una particular gravedad". La doctrina, en la materia, ha sostenido la posibilidad de demandar daños patrimoniales de "una particular gravedad" como consecuencia de la disolución, por ejemplo, gastos exorbitantes para establecerse en una nueva residencia con los hijos comunes. Pero es necesario efectuar varias distinciones. Si ambos cónyuges cuentan con recursos suficientes para sustentar su vida, y la de los hijos comunes, luego del divorcio, un daño de esta naturaleza no se presentará. Para el caso que sólo uno de ellos cuente con recursos suficientes al momento de la disolución, usualmente el problema se resolverá mediante la prestación compensatoria que el juez, en estos casos, usualmente otorga al otro. Por lo demás, el actual artículo 266 prohíbe plantear luego del divorcio la acción de responsabilidad que reconoce, por lo que las necesidades económicas "particularmente graves" que surjan luego de ese suceso, no podrán ser resueltas invocando esta norma ${ }^{55}$. Para el caso que ninguno de ellos cuente con recursos suficientes, muy probablemente para ambos el divorcio tendrá consecuencias patrimoniales de una "particular gravedad", al tener que asumir los gastos ordinarios sólo con sus recursos y sin contar con la colaboración del otro. En tales casos, lamentablemente, es muy probable que ninguno de ellos tenga derecho a prestación compensatoria, y en caso de exigirse una indemnización al amparo del artículo 266 y ser concedida, ella será simbólica o quedará sin ejecución en caso de no serlo ${ }^{56}$.

Como sea, en la práctica judicial un perjuicio patrimonial de una "particular gravedad" es muy raro que se invoque, pues frecuentemente es difícil de distinguir de la disparidad de condiciones materiales de vida que se aborda y soluciona con la prestación compensatoria ${ }^{57}$. Así, la jurisprudencia ha concluido claramente que no puede concederse la indemnización de este artículo 266 si la disparidad en las condiciones materiales producto de la disolución del matrimonio puede resolverse con la prestación compensatoria ${ }^{58}$.

Asimismo, las Cortes de Apelaciones - tal como lo concluye la doctrina - han aplicado restrictivamente este artículo en lo concerniente a los perjuicios patrimoniales, concluyendo que no envuelve una consecuencia de una "particular gravedad", por ejemplo, la sensible disminución de recursos de un cónyuge y el hecho de tener que vivir en condiciones ma-

\footnotetext{
55 Ibidem, p. 378.

${ }^{56}$ Garrigue, Jean, cit. (n. 50), pp. 378 y 379.

57 Vid. en este sentido: KeSsLer, Guillaume, cit. (n. 11), p. 20.

${ }^{58}$ Corte de Apelaciones de Douai, sección 7, 2 de abril de 2015, №14/04441.
} 
teriales muy inferiores al estado anterior ${ }^{59}$. La sola posibilidad de obtener una reparación patrimonial conforme a esta norma, es la justificación de una condición material extremadamente difícil y grave, mucho más allá de la simple disparidad de condiciones de vida que provoca la disolución, como cuando la madre tiene que hacerse cargo de hijos enfermos ${ }^{60} \mathrm{o}$ cuando ella misma se encuentra gravemente discapacitada producto de una enfermedad y sin poder generar recursos ${ }^{61}$. En otro caso, que muestra la dificultad de distinguir los dos estatutos de responsabilidad, una Corte de Apelaciones afirmó que sólo sobre la base del derecho común podría demandarse la indemnización de perjuicios provocados a una mujer que se consagró durante 24 años a la educación de los hijos y que luego había sido obligada a abandonar el domicilio conyugal, debiendo vivir de allegada donde familiares por carecer de recursos ${ }^{62}$.

En la materia, por tanto, se presenta la constante de una apreciación muy restrictiva de las condiciones para proceder a la indemnización de perjuicios patrimoniales en virtud de este artículo 266, al mismo tiempo de dar lugar a similares problemas de distinción entre los dos estatutos aplicables.

ii) En cuanto al daño moral, las decisiones son más abundantes, al menos de segunda instancia. En efecto, la Corte de Casación ha aplicado también de forma muy restrictiva este artículo, al punto que entre los años 2005 y 2009 concluyó que el daño moral sólo podía demandarse conforme a las normas del derecho común (artículo 1382), posición que sólo abandonó en el año $2010^{63}$. Al parecer, esta Corte entendía que usualmente estos daños no provienen de la disolución, sino de hechos anteriores, como el adulterio en condiciones escandalosas ${ }^{64}$, dando prueba, una vez más, de las dificultades que presenta la distinción entre los dos regímenes.

En todo caso, el daño moral que puede calificarse como una consecuencia de una "particular gravedad" atiende a padecimientos morales que "salen de lo ordinario", pues en el "divorcio, el sufrimiento es la regla" 65 .

En realidad, sólo es posible identificar un fallo de la Corte de Casación

${ }^{59}$ Corte de Apelaciones de París, polo 3, Sala 3a, 9 de abril de 2015, No13/18059.

${ }^{60}$ Corte de Apelaciones de Orléans, Sala Familia, 10 de marzo de 2015, No13/03760.

${ }^{61}$ Corte de Apelaciones de Metz, Sala Familia, 17 de febrero de 2015, No13/02432.

${ }^{62}$ Corte de Apelaciones de Versailles, 2a Sala, sección 1, 7 de mato de 2015, No14/00810.

${ }^{63}$ Corte de Casación, $1^{\text {a }}$ Sala Civil, 3 de febrero de 2010, No09-10.109.

${ }^{64}$ Corte de Casación, 1 a Sala Civil, 25 de abril de 2007, No06-17.095.

${ }^{65}$ Garrigue, Jean, cit. (n. 50), p. 379. 
que, clara y categóricamente, acepta calificar un perjuicio "moral" como una consecuencia de una "particular gravedad" y lo indemniza. En la especie, se trataba de un abandono del hogar común por parte de la mujer, dejando al marido durante 5 años a cargo de dos hijos, uno de ellos con problemas psiquiátricos, cuestión que lo condujo a sacrificar su carrera profesional ${ }^{66}$. Como lo ha señalado un autor, la decisión resulta muy discutible, por la circunstancia de que tales daños no parecían provenir de la disolución (sino de hechos anteriores) y, en todo caso, porque parte de lo alegado (sacrificio de carrera) es propio de aquello que se resuelve con la prestación compensatoria ${ }^{67}$.

En paralelo existen innumerables fallos de la Corte de Casación que revocan decisiones de las Corte de Apelaciones que habían calificado ciertos daños morales como "consecuencias de una particular gravedad" luego de la disolución ${ }^{68}$.

Y, en este sentido, tal vez el fallo más elocuente de la Corte de Casación es el de $1^{\circ}$ de julio de $2009^{69}$. El fallo revocó una decisión de apelación que había concedido la indemnización del daño moral sobre la base de este artículo 266, concluyendo que abandonar a su cónyuge por una nueva pareja, luego de 39 años de matrimonio y en condiciones difíciles, no genera esas consecuencias de una particular gravedad ${ }^{70}$. Como el divorcio había sido concedido por culpa exclusiva del marido, esta dura decisión muestra la percepción de la jurisprudencia, una vez más, en orden a que el divorcio por culpa envuelve en sí mismo una especie de sanción. Asimismo, esto prueba las dificultades para definir la magnitud del daño y darle contenido a esta inédita fórmula de "consecuencias de una particular gravedad", y la excepcionalidad con que se termina aplicando este estatuto.

Los pocos casos en que se ha aceptado la configuración de la magnitud de este daño por las Cortes de Apelaciones (aunque, de estas decisiones, aquellas que llegan a la Corte de Casación han sido revocadas) ${ }^{71}$ se tratan de situaciones completamente excepcionales, tales como: el perjuicio moral que causa el divorcio para un cónyuge católico (religión que, como se sabe, no lo tolera), bajo condición demostrar fehacientemente su "fervor religioso" (por ejemplo, ser parte de asociaciones confesionales) ${ }^{72}$; o un

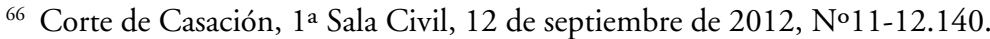

${ }^{67}$ CASEY, Jérôme, cit. (n. 14), p. 17.

${ }^{68}$ Ibidem.

${ }^{69}$ Corte de Casación, $1^{\text {a }}$ Sala Civil, $1^{\circ}$ de julio de 2009, No08-17.825.

${ }^{70}$ Corte de Casación, $1^{\text {a }}$ Sala Civil, $1^{\circ}$ de julio de 2009, No08-17.825. Vid. un comentario en PIWNICA, Dominique, cit. (n. 37), pp. 44 y 45.

${ }^{71}$ Vid. al respecto las estadísticas mencionadas, cit. (n. 6).

72 Corte de Apelaciones de París, polo 3, 3a Sala, 26 de febrero de 2015, 
divorcio que tuvo lugar en un país distinto a la nacionalidad de la esposa, en el cual no tenía familia, quedando sola ${ }^{73}$. En otras ocasiones, las Cortes de Apelaciones, de forma equivocada, han puesto atención no sólo al perjuicio y a su gravedad, sino también a la culpa (cuestión que justifica en parte el que varios de estos fallos sean revocados), como el caso en que se condenó a un marido por la actitud "perversa" de hacer creer a su mujer en una posible reconciliación, mientras seguía viviendo con su amante ${ }^{74}$ (pero en otro caso idéntico, se concluyó lo contrario ${ }^{75}$ ), o en otro en que un marido también fue condenado por instar a que su mujer dejara su trabajo para seguirlo a otra ciudad, para luego abandonarla embarazada ${ }^{76}$. Como se entiende, en estos últimos fallos subyace la confusión con el estatuto del artículo 1382, fundado en la culpa y relativo a hechos anteriores a la disolución y no a daños provocados por ésta ${ }^{77}$.

iii) Otra constatación importante es que la elección del régimen, tal como ocurría con la redacción anterior de la norma de 1975, sigue siendo muy relevante. Por esto, es común que los abogados aleguen un estatuto y subsidiariamente otro. La equivocación en el estatuto puede ser fatal cuando la jurisprudencia estima, en particular, que los daños, aunque graves, provienen de hechos anteriores a la disolución, como el caso en que una mujer, insultada y maltratada por el marido y la familia de éste, es llevada de regreso a la fuerza a su país natal. La indemnización no pudo otorgarse en este lamentable caso, porque el abogado había mal fundado su demanda sobre la base del artículo 266 y no sobre el artículo $1382^{78}$. En efecto, la Corte de Casación es constante en señalar que no pueden indemnizarse, bajo el amparo del artículo 266, los perjuicios que no provienen directamente de la disolución, aunque la distinción, como se ha expuesto, no es fácil en la práctica.

iv) Asimismo, la aplicación de este artículo en la jurisprudencia muestra una paradoja, pues sobre la base del artículo 1382 en ocasiones se han reparado perjuicios que no son de una "particular gravedad", bajo la

\section{No13/11805.}

73 Corte de Apelaciones de París, 24a Sala, sección A, 20 de febrero de 2008, JurisData, No2008-356143.

74 Corte de Apelaciones de Chambéry, 3a Sala, 17 de marzo de 2015, No14/01051.

75 Corte de Apelaciones de Nancy, 3a Sala Civil, 30 de marzo de 2015, No14/00783.

76 Corte de Apelaciones de Orléans, Sala Familia, 17 de marzo de 2015, No13/02387.

77 Vid. en este sentido: KessLer, Guillaume, cit. (n. 9), p. 21.

${ }^{78}$ Corte de Apelaciones de Montpellier, 1a Sala, sección C, 7 de enero de 2015, No14/03205. 
condición de que se pruebe una culpa calificada, según se expuso. Ahora bien, en caso de disolución, esta posibilidad no existe, pues el artículo 266 exige la "particular gravedad" y no es posible invocar el artículo 1382, pues se trata de daños provenientes de la disolución ${ }^{79}$.

v) Por último, debe señalarse que las sumas otorgadas en virtud de este artículo 266, son incluso más bajas que las concedidas bajo el régimen común, fluctuando en 3.000 euros en promedio ${ }^{80}$. Esto constituye una paradoja si consideramos que se trata de "consecuencias de una particular gravedad", cuestión que grafica un panorama de aplicación muy limitado y "decepcionante" 81 .

Ello explica que algunos autores se interroguen sobre la "necesidad de mantener el artículo 266 del Código Civil, cuando todos los perjuicios pueden ser reparados sobre la base del derecho común, estén ligados o no a la disolución del matrimonio"82.

En síntesis, además de las asimetrías entre los regímenes (uno fundado en la culpa calificada, otro en los perjuicios particularmente graves, sin culpa), lo cierto es que la práctica francesa muestra una aplicación errática que se explica en parte porque es difícil discernir de dónde provienen los daños (de hechos anteriores que provocan la disolución o de la disolución) y, por ello, todo hace presagiar que el artículo 266 tiene un futuro "muy limitado"83.

Al término de este artículo, y a pesar de no ser evidentemente el objeto principal del mismo, parece útil efectuar, a título meramente ilustrativo, ciertas comparaciones con lo resuelto por la jurisprudencia chilena. Ante todo, cabe destacar que este tema ha sido ampliamente estudiado por la doctrina nacional de la última década, a través de aproximaciones divergentes, que probablemente se explican en parte por diferentes interpretaciones de los fallos dictados en la materia ${ }^{84}$. De ahí que me haya parecido oportuno

${ }^{79}$ Vid. al respecto, Mulon, Élodie, Dommages-intérêts en matière de divorce: pour une suppression de l'article 266 du Code civil en Gazzete du Palais, Édition Spécialisée 19 y 21 (2014), pp. 99 y ss.

${ }^{80}$ CaSEY, Jérôme, cit. (n. 14), p. 17

${ }^{81}$ Ibidem. Vid. también las estadísticas mencionadas, cit. (n. 5 y n. 6).

${ }^{82}$ Mulon, Élodie, cit. (n. 81), p. 107.

${ }^{83}$ CaSey, Jérôme, cit. (n. 14), p. 17.

${ }^{84}$ Sobre el particular, destaco los siguientes estudios chilenos recientes: BARCIA Lehmann, Rodrigo y Rivera Restrepo, José, ¿En qué casos el incumplimiento de deberes del matrimonio genera responsabilidad civil? en Revista Ius et Praxis, 21-2 (2015), pp. 19-60; Bravo SiLVA, Daniel, Responsabilidad civil entre cónyuges y excónyuges, por hechos cometidos durante el matrimonio: panorama jurisprudencial en Chile, con especial referencia a la sentencia de la Corte de Apelaciones de La Serena de 3 de abril de 2014, en Vidal, Álvaro, SEverin, Gonzalo y Mejías, Claudia (coords.), Estudios 
realizar un análisis jurisprudencial de un sistema próximo al nuestro, como

de derecho civil X, Jornadas nacionales de derecho civil, Valparaiso 2014 (Santiago, LegalPublishing-Thomson Reuters, 2015) pp. 249-265; Corral TalCiani, Hernán, La incipiente jurisprudencia chilena sobre daños en la familia en Revista de Derecho de Familia 4 (2014), pp. 51-59; Etcheberry Court, Leonor, cit. (n. 33); HeraNE VIVES, Francisco, Reparación por incumplimiento de los deberes matrimoniales, en Corral, Hernán y Rodríguez, María Sara (coords.), Estudios de Derecho Civil II. Jornadas nacionales de derecho civil, Olmué, 2006 (Santiago, Editorial LexisNexis, 2006), pp. 181-193; HeRnándeZ PAulsen, Gabriel, Las consecuencias de la infracción de deberes matrimoniales no dan lugar a indemnización en Revista chilena de derecho privado 27 (2016), pp. 95-139; LARROUCAU GarCía, Matilde, De la naturaleza y características del derecho de familia y del adulterio como fuente generadora de responsabilidad civil, comentario de jurisprudencia, en Revista chilena de derecho de familia 2 (2010), pp.199-206; LePín Molina, Cristián, Responsabilidad civil en las relaciones de familia, en Lepin Molina, Cristián (dir.) y Vargas Aravena, David (coord.), Responsabilidad civil y familia (Santiago, Thomson Reuters, 2014), pp. 397-438; Novales Alquézar, Aránzazu, Responsabilidades especiales. ¿Debiera haber en el derecho matrimonial mecanismos reparatorios? en Regimenes especiales de responsabilidad civil. Cuadernos de análisis jurídicos. Colección Derecho Privado IV (Santiago, Ediciones de la Universidad Diego Portales, 2008), pp. 119-150; Opazo GonZÁlEZ, Mario, El principio de la reparación integral del daño y los daños causados por adulterio, en ELORRIAGA Fabián (coord.), Estudios de derecho civil VII. Jornadas nacionales de derecho civil, Viña del Mar, 2011 (Santiago, AbeledoPerrot, 2012), pp. 589-605; OTÁrola EsPinOza, Yasna, La culpa en materia de derecho matrimonial, en Domínguez Hidalgo, Carmen, González Castillo, Joel, Barrientos Zamorano, Marcelo y GoldenBERG Serrano, Juan Luis (coords.), Estudios de derecho civil VIII. Jornadas nacionales de derecho civil, Santa Cruz, 2012 (Santiago, LegalPublishing, 2013), pp. 125-134, y La naturaleza obligacional de los deberes matrimoniales, en TURnER, Susan y VARAS, Juan Andrés, Estudios de derecho civil IX, Jornadas nacionales de derecho civil, Valdivia 2013 (LegalPublishing-Thomson Reuters, 2014), pp. 183-195; QuinTana Villa, María Soledad, Aplicación jurisprudencial de las nuevas causales de terminación del matrimonio en Revista de Derecho de la Pontificia Universidad Católica de Valparaíso 31(2008), pp. 267-288; SEVERIn Fuster, Gonzalo, cit. (n. 33), e Incompetencia del Tribunal de Familia para conocer las demandas de daño por infracción de los deberes conyugales, en Pizarro WiLson, Carlos (coord.), Estudios de derecho civil IV Jornadas Nacionales de Derecho Civil, Olmué, 2008, (Santiago, LegalPublishing, 2009), pp. 247-260; Turner SAelzer, Susan, Deberes personales derivados del matrimonio y daños en la jurisprudencia chilena, en Domínguez Hidalgo, Carmen, González Castillo, Joel, Barrientos Zamorano, Marcelo y Goldenberg Serrano, Juan Luis (coords.), Estudios de derecho civil VIII. Jornadas nacionales de derecho civil, Santa Cruz, 2012 (Santiago, LegalPublishing, 2013), p. 165-173; VAlenZuela del Valle, Jimena, Responsabilidad civil por el incumplimiento de obligaciones matrimoniales $y$ por el ejercicio abusivo del divorcio unilateral. Un estudio de su admisibilidad en Chile, en Revista de Derecho Universidad Católica del Norte 19-1 (2012), pp. 241-269; y, Vargas Aravena, David, Del divorcio y la responsabilidad civil, en Revista de Derecho de Familia, 3 (2014), pp. 139-148, y Del resarcimiento en Chile de los daños causados 
es el francés, de forma de aportar de alguna manera al debate. Del examen de la jurisprudencia nacional sobre la materia, pueden identificarse los siguientes desarrollos convergentes y divergentes respecto de la experiencia francesa: i) Por una parte, llama la atención el universo limitado de fallos en Chile, al menos de segunda instancia y Corte Suprema, pronunciados sobre la materia. En mi conocimiento, y luego de una revisión concienzuda realizada para otras publicaciones ${ }^{85}$, existen siete fallos relevantes y recientes sobre la materia ${ }^{86}$. En ese sentido, se percibe incluso una aplicación más restrictiva que en la práctica francesa. Es cierto, en el derecho chileno no existe una norma especial equivalente al artículo 266 del Código Civil francés (aunque, como se ha expuesto en este trabajo, de escasa aplicación práctica), pero resulta inequívoco que los artículos 2314 y siguientes del Código Civil chileno habilitan a los jueces, en términos idénticos al artículo 1382 de su homólogo francés, a extender la responsabilidad a cualquier hipótesis de daño causado con culpa o dolo en el divorcio, cuestión que en el caso chileno no se ha llevado a cabo. ii) Por otra parte, de ese universo de fallos, seis rechazan la indemnización y sólo uno, proveniente de la Corte Suprema, lo concede. Se trata del importante fallo de 30 de diciembre de $2014^{87}$, que es el más categórico y extenso pronunciamiento de la Corte sobre la procedencia o improcedencia de la indemnización de perjuicios entre cónyuges luego del divorcio culpable. El fallo, en síntesis, declara procedente tal indemnización cuando existe vulneración de derechos protegidos, como la integridad psíquica o física de uno de los cónyuges y, al mismo tiempo, es categórico en excluirla cuando se funda en la mera infracción de deberes personales conyugales, como la fidelidad. En efecto, concluye que "más allá de las disquisiciones doctrinarias sobre la proce-

en el matrimonio, en Revista Ius et Praxis 21-1 (2015), pp. 57-100. Vid. también las publicaciones del autor de este artículo mencionadas en cit. (n. 33).

${ }^{85}$ En particular, TAPIA, Mauricio, Divorcio, cit. (n. 21), pp. 139-198. También en el artículo inédito: Improcedencia de la indemnización por incumplimiento de deberes conyugales en la jurisprudencia chilena, en Presente y futuro de la responsabilidad civil, Universidad Alberto Hurtado, en prensa.

${ }^{86}$ Tales fallos, son los siguientes: Corte de Apelaciones de Valdivia, de 8 de agosto de 2007 (Rol No411-2007); Corte de Apelaciones de Rancagua, 29 de octubre de 2007 (Rol No 672-07); Corte de Apelaciones de Santiago, 10 de noviembre de 2009, confirmada por la Corte Suprema, 13 de junio de 2012 (Rol No 7738-2007); Corte de Apelaciones de Santiago, de 4 de noviembre de 2010 (Rol No 890-2010); Corte de Apelaciones de Puerto Montt, 20 de diciembre de 2010, confirmada por la Corte Suprema, 6 de marzo de 2012 (Rol No 778-2011); Corte de Apelaciones de Talca, de 30 de agosto de 2012 (Rol No 133-2012); y, Corte Suprema, 30 de diciembre de 2014 (Rol No 10.622-2014).

${ }^{87}$ Corte Suprema, 30 de diciembre de 2014 (Rol No 10.622-2014). 
dencia de la reparación por el incumplimiento de deberes matrimoniales, en la especie se ha determinado la responsabilidad civil del demandado como consecuencia de acreditarse el deterioro emocional o psicológico que le ha causado a la actora fruto de sus conductas antijurídicas que han motivado el divorcio por culpa" (considerando $7^{\circ}$ ). En este sentido se percibe un punto de encuentro y otro de desencuentro con la experiencia francesa. En primer lugar, existe coincidencia en ambos sistemas sobre la procedencia de la indemnización luego del divorcio cuando las causales que lo han motivado envuelven la vulneración de otros bienes jurídicos protegidos (como la integridad física o psíquica de un cónyuge ${ }^{88}$. En segundo lugar, es perceptible una visión de la jurisprudencia nacional más restrictiva que la francesa en cuanto a la procedencia de la indemnización por incumplimiento de deberes conyugales, en particular, por adulterio. Tal posición puede tal vez explicarse por los argumentos que esgrime la Corte de Apelaciones de Santiago, en el fallo de 10 de noviembre de $2009^{89}$, en orden a que la especialidad del derecho de familia impediría extrapolarle las normas generales de la responsabilidad civil y que, a mayor abundamiento, no podría considerarse el adulterio un ilícito civil que pueda cometerse con culpa o con dolo.

Para concluir, y volviendo al objeto central de este artículo, sea que se mantenga la dualidad o se unifiquen los estatutos en Francia, todo hace prever que la jurisprudencia francesa seguirá concediendo - como lo ha hecho sistemáticamente - una indemnización de perjuicios entre cónyuges (por bajísimos montos) $^{90}$, tanto por los hechos que dan lugar al divorcio o por la disolución misma, sólo en hipótesis muy excepcionales, por culpas calificadas, lesión de otros bienes jurídicos (como la integridad física) o daños particularmente graves, pues subyace en ella la idea - como se expuso - de que todo divorcio acarrea necesariamente sufrimientos morales y penurias materiales, que deben, lamentablemente, ser soportados por cada cónyuge.

\section{BiBLIOGRAFÍA}

Barcia Lehmann, Rodrigo y Rivera Restrepo, José, ¿En qué casos el incumplimiento de deberes del matrimonio genera responsabilidad civil? en Revista Ius et Praxis, 21-2 (2015).

${ }^{88}$ Véase al respecto, los trabajos de los profesores Gonzalo SEVERIN (citado por el fallo en comento) y Leonor ETCHEBERRY, cit. (n. 33).

${ }^{89}$ Corte de Apelaciones de Santiago, 10 de noviembre de 2009, confirmada por la Corte Suprema, 13 de junio de 2012 (Rol No 7738-2007);

90 Vid. al respecto lo expuesto en cit. (n. 5 y n. 6). 
Bravo Silva, Daniel, Responsabilidad civil entre cónyuges y excónyuges, por hechos cometidos durante el matrimonio: panorama jurisprudencial en Chile, con especial referencia a la sentencia de la Corte de Apelaciones de La Serena de 3 de abril de 2014, en Vidal, Álvaro, Severin, Gonzalo y Mejías, Claudia (coords.), Estudios de derecho civil X, Jornadas nacionales de derecho civil, Valparaiso 2014 (Santiago, LegalPublishing-Thomson Reuters, 2015).

Carbonnier, Jean, Droit civil. Introduction. Les personnes. La famille, l'enfant, le couple (París, Quadrige/PUF, 2004).

Carbonnier, Jean, Le divorce, en Essais sur les lois (París, Répertoire du Notariat Defrénois, 1995, 2a ed.)

CARVAL, Suzanne, La responsabilité civile dans sa fonction de peine privée (París, LGDJ, 1995).

CASEy, Jérôme, Articles 1382 et 266 du Code civil. Analyse de jurisprudence et synthèse en Droit de la famille, 7 y 8 (2015).

Corral TAlCIANI, Hernán, La incipiente jurisprudencia chilena sobre daños en la familia en Revista de Derecho de Familia 4 (2014).

Chabas, François, Cien años de responsabilidad civil en Francia (París, van Dieren, 2004, traducción y notas de Mauricio TAPIA).

ETCHEBERry COURT, Leonor, Responsabilidad civil ante el quebrantamiento del deber de fidelidad entre los cónyuges. Corte Suprema, 13 de junio de 2012, comentario de jurisprudencia, en Revista chilena de derecho privado 19 (2012).

GarRIgUE, Jean, Les devoirs conyugaux. Réflexion sur la consistance du lien matrimonial (París, Éditions Panthéon Assas, Thèses, 2012).

HAUSER, Jean, Le divorce nouveau et la responsabilité en Droit et patrimoine 136 (2005).

Herane Vives, Francisco, Reparación por incumplimiento de los deberes matrimoniales, en Corral, Hernán y Rodríguez, María Sara (coords.), Estudios de Derecho Civil II. Jornadas nacionales de derecho civil, Olmué, 2006 (Santiago, Editorial LexisNexis, 2006).

HeRnández Paulsen, Gabriel, Las consecuencias de la infracción de deberes matrimoniales no dan lugar a indemnización en Revista chilena de derecho privado 27 (2016).

KeSSLER, Guillaume, Les dommages et intérêts dans le divorce: panorama de jurisprudence en Droit de la famille 7 y 8 (2015).

Lafon, Catherine, Panorama de jurisprudence. Dommages- intérêts entre époux dans les décisions de cours d'appel, en Droit de Famille 7 y 8 (2015).

LARRoucau García, Matilde, De la naturaleza y características del derecho de familia y del adulterio como fuente generadora de responsabilidad civil, comentario de jurisprudencia, en Revista chilena de derecho de familia 2 (2010).

Lepin Molina, Cristián, Responsabilidad civil en las relaciones de familia, en LEPIN Molina, Cristián (dir.) y Vargas Aravena, David (coord.), Responsabilidad civil y familia (Santiago, Thomson Reuters, 2014).

Novales AlquéZAR, Aránzazu, Responsabilidades especiales. ¿Debiera haber en el derecho matrimonial mecanismos reparatorios? en Regimenes especiales de responsabilidad civil. Cuadernos de análisis jurídicos. Colección Derecho Privado IV (Santiago, Ediciones de la Universidad Diego Portales, 2008).

Mulon, Élodie, Dommages-intérêts en matière de divorce: pour une suppression de l'article 266 du Code civil en Gazzete du Palais, Édition Spécialisée 19 y 21 (2014).

Opazo GonzÁlez, Mario, El principio de la reparación integral del daño y los daños causados por adulterio, en ElORRIAGa Fabián (coord.), Estudios de derecho civil VII. 
Jornadas nacionales de derecho civil, Viña del Mar, 2011 (Santiago, AbeledoPerrot, 2012).

OtÁRola EsPinoza, Yasna, La culpa en materia de derecho matrimonial, en DOMÍnGUEZ Hidalgo, Carmen, González Castillo, Joel, Barrientos Zamorano, Marcelo y Goldenkerg SERRANO, Juan Luis (coords.), Estudios de derecho civil VIII. Jornadas nacionales de derecho civil, Santa Cruz, 2012 (Santiago, LegalPublishing, 2013).

OtÁrola EsPINOZA, Yasna, La naturaleza obligacional de los deberes matrimoniales, en Turner, Susan y VArAS, Juan Andrés, Estudios de derecho civil IX, Jornadas nacionales de derecho civil, Valdivia 2013 (LegalPublishing-Thomson Reuters, 2014).

Pierroux, Emmanuèle, En mariage, ton époux tu honoreras! en Gazette du Palais 2324 (2011).

Piwnica, Dominique, Les dommages et intérêts de l'article 266 du Code civil dans la loi du 26 mai 2004 en La Semaine Juridique, Édition Générale 45 (2009).

PizArRo, Laura, L'épouse créancière de dommages et intérêts pour abstinence sexuelle préjudiciable en La Semaine Juridique, Édition Générale 43-44 (2011).

Pons, Stéphanie, La réception par le droit de la famille de l'article 1382 du Code civil, (Aix-en-Provence, PUAM, 2007).

Quintana Villa, María Soledad, Aplicación jurisprudencial de las nuevas causales de terminación del matrimonio en Revista de Derecho de la Pontificia Universidad Católica de Valparaíso 31(2008).

SCHOUfLIKIR, Anaïs (coord.), Dossier: Les dommages et intérets entre époux, en Droit de Famille 7 y 8 (2015).

SeVerin Fuster, Gonzalo, Incompetencia del Tribunal de Familia para conocer las demandas de daño por infracción de los deberes conyugales, en PizArRo WiLsON, Carlos (coord.), Estudios de derecho civil IV. Jornadas nacionales de derecho civil, Olmué, 2008, (Santiago, LegalPublishing, 2009).

SEVERIN Fuster, Gonzalo, Indemnización entre cónyuges por los daños causados con ocasión del divorcio, en GUZMÁn BRITO, Alejandro (ed.), Estudios de Derecho Civil III. Jornadas nacionales de derecho civil, Valparaíso, 2007 (Santiago, LegalPublishing, 2008).

TAPIA, Mauricio, Nulidad y divorcio en el proyecto de nueva Ley de Matrimonio civil, en Revista Estudios Públicos 86 (2002).

TAPIA, Mauricio, Código Civil. 1855-2005. Evolución y perspectivas (Santiago, Editorial Jurídica de Chile, 2005).

TAPIA, Mauricio, Aproximación crítica a la indemnización de perjuicios por incumplimiento de deberes conyugales en VIDAL Álvaro, SEverin Gonzalo y Mejías Claudia (coord.), Estudios de derecho civil X, Jornadas nacionales de derecho civil, Valparaíso 2014 (Santiago, LegalPublishing-Thomson Reuters, 2015).

TAPIA, Mauricio, Divorcio y responsabilidad civil en el derecho chileno en Revista de Derecho Universidad de Concepción 239, (2016).

TAPIA, Mauricio, Contra la indemnización de perjuicios por incumplimiento de deberes conyugales, en LEPÍN, Cristián y GÓMEZ DE LA TORRE, Maricruz (coord.), Estudios de derecho familiar I. Actas primeras jornadas nacionales. Facultad de Derecho Universidad de Chile (Santiago, Thomson Reuters, 2016).

TAPIA, Mauricio, El incumplimiento de deberes conyugales no da lugar a la indemnización de perjuicios (Corte Suprema, 30 de diciembre de 2014) en Revista de Estudios Judiciales, 2 y 3 (2016) 
TAPIA, Mauricio, Divorcio y responsabilidad civil en el derecho chileno en Revista de Derecho Universidad de Concepción, 239 (2016).

TAPIA, Mauricio, Improcedencia de la indemnización por incumplimiento de deberes conyugales en la jurisprudencia chilena, en Presente y futuro de la responsabilidad civil, Universidad Alberto Hurtado, en prensa.

Turner Saelzer, Susan, Deberes personales derivados del matrimonio y daños en la jurisprudencia chilena, en Domínguez Hidalgo, Carmen, González Castillo, Joel, Barrientos Zamorano, Marcelo y Goldenberg Serrano, Juan Luis (coords.), Estudios de derecho civil VIII. Jornadas nacionales de derecho civil, Santa Cruz, 2012 (Santiago, LegalPublishing, 2013).

Valenzuela del Valle, Jimena, Responsabilidad civil por el incumplimiento de obligaciones matrimoniales y por el ejercicio abusivo del divorcio unilateral. Un estudio de su admisibilidad en Chile, en Revista de Derecho Universidad Católica del Norte 19-1 (2012).

Vargas Aravena, David, Del divorcio y la responsabilidad civil, en Revista de Derecho de Familia, 3 (2014), pp. 139-148, y Del resarcimiento en Chile de los daños causados en el matrimonio, en Revista Ius et Praxis 21-1 (2015).

VINEY, Geneviève, Introduction à la responsabilité (París, L.G.D.J., 2008, 3ª ed.) 